\title{
Consideraciones sobre elementos de la arquitectura y la venustas en Vitruvio y en San Isidoro. Similitudes y diferencias
}

\author{
Rafael García Sánchez \\ Universidad Politécnica de Cartagena
}

\section{RESUMEN}

Vitruvio e Isidoro de Sevilla hacen referencia a la venustas. Sin embargo, el sentido que se le otorga en De Architectura difiere en lo sustancial al que aparece en las Etimologías. En este artículo nos proponemos constatar tales diferencias, lo que nos lleva a concluir que el hispalense no fundamenta su noción de arquitectura en el tratado vitruviano.

\section{ABSTRACT}

Vitruvius and Isidore of Seville make reference to the venustas. However, the sense of it in De Architectura differs in substance with which appears in the Etymologies. In this article we intend to verify such differences, which leads us to conclude that the Seville does not base his notion of architecture on the vitruvian treated.

\section{PALABRAS CLAVE}

Vitruvio, Isidoro de Sevilla, Venustas, Pulchritudo, Arquitectura.

\section{KEYWORDS}

Vitruvio, Isidoro de Sevilla, Venustas, Pulchritudo, Architecture. 


\section{Introducción}

Isidoro de Sevilla (560-636), último de los padres de la Iglesia de Occidente y compilador de la cultura clásica ${ }^{1}$ hizo referencia a la belleza arquitectónica en sus Etimologias ${ }^{2}$. Cervera Vera $^{3}$ ve trazas directas de Vitruvio (s. I a.C.) en la enciclopédica obra del hispalense. Señala que entre las fuentes manejadas por Isidoro "se encontraban dos obras de Vitruvio: De architectura y De diversis fabricis architectonicis"4 y defiende que lo leyó con la intención de perpetuar parte del conocimiento de la Antigüedad. Kruft, por el contrario, sentencia que "Si se leen las opiniones básicas de Isidoro sobre arquitectura [...] se verá con claridad que difícilmente pudo haberse apoyado en Vitruvio. [...]. La utilización que hace Isidoro de conceptos que parecen vitruvianos no corresponde en su contenido a las definiciones de Vitruvio"5. Isabel Velázquez ofrece una postura intermedia $^{6}$. Duda ${ }^{7}$ que Isidoro de Sevilla manejase Los diez libros de arquitectura de Vitruvio ${ }^{8}$, lo que no le impide indicar que este fuera visible a través los comentarios de Servio sobre Virgilio, en algunos de Varrón, en los de historia de Plinio, en el De re rustica de Rutilio Paladio ${ }^{9}$ o en los textos de estética de Agustín de Hipona. Con todo, y aceptando que Vitruvio estuviese

HIRSCHBERGER, Johannes, Historia de la filosofía I. Antigüedad, Edad Media, Renacimiento, Herder, Barcelona, 2007, pp. 404-405. BEESON, Charles H., Isidor-Studien, CH Beck, München,1913, pp. 3.

2 SAN ISIDORO DE SEVILLA, Etimologías, Biblioteca de autores cristianos, Madrid, 2004.

3 CERVERA VERA, Luis, "Algunas definiciones urbanísticas y arquitectónicas de San Isidoro de Sevilla" en Anales de Historia del arte, 4, Madrid, 1994, pp. 71-82.

4 CERVERA VERA, Luis, "Algunas definiciones urbanísticas y arquitectónicas de San Isidoro de Sevilla”, opus cit., pp.71.

5 KRUFT, Hanno-Walter, Historia de la teoría de la arquitectura. Desde la Antigüedad hasta el siglo XVIII, Alianza Forma, Madrid, 1990, pp. 35-36.

6 VELÁZQUEZ, Isabel, “Aedificiorum venustas: la recepción de un término clásico en Isidoro de Sevilla (Etym., XIX 11) en Antigüedad y cristianismo, 14, Murcia, 1997, pp. 241.

7 Sigue a DÍAZ Y DÍAZ, Manuel Cecilio, De Isidoro al siglo XIX. Ocho estudios sobre la vida literaria peninsular. Ediciones El Albir, Barcelona, 1976, pp. 35.

8 Para los textos en latín, VITRUVII, De Architectura Libri Decem, (Edidit et annotavit Curt Fensterbusch), Wissenschaftliche Buchgesellschaft, Darmstadt, 1976. (VITRUV, Zehn Bücher Über Architektur).

9 Para esta cuestión es revelador MORTET, Victor, "Recherches critiques sur Vitruve et son ouvre" en Revue archéologique, II, Vitruve et les vitruvius, (1902), pp. 45-69. presente en los escritos de los que se sirviese Isidoro para la redacción de las Etimologias, nos proponemos realizar algunas consideraciones sobre los elementos de la arquitectura y la venustas allí señalada, pues difiere de la contenida en el tratado vitruviano.

Aunque Isabel Velázquez ha realizado un lúcido y sólido análisis al respecto, nos proponemos profundizar aún más en el alcance conceptual de la venustas, dado que en la definición que ofrece el hispalense aflora un sentido, a nuestro juicio, diferente al vitruviano, sin menoscabo de que uno y otro defendieran una noción reglada del arte. Como es sabido, el romano desconfiaba de aquellos artífices que construían ayunos de normas y preceptos, y así se lo hizo notar a Augusto en el proemio del Libro III ${ }^{10}$. En el proemio al libro VI insistirá sobre este particular denunciando que muchos de los arquitectos que han hecho fortuna en su época han alcanzado la fama sin observar las reglas de la arquitectura, incluso de otras muchas artes ${ }^{11}$. El hispalense realizará una advertencia similar, y no con menor contundencia, en el libro XX de las Etimologias: "Norma [...] extra quam nihil rectum fieri potest" ${ }^{2}$. Para ambos autores, no están permitidas la licencia ni la ignorancia normativa en la arquitectura, tampoco el subjetivismo estético. En cualquier caso, es llamativo que tanto Vitruvio como Isidoro utilicen el término venustas para referirse a la belleza arquitectónica.

En De Archiectura, la venustas aparece en el capítulo III del libro I y está vinculada al aspecto agradable del edificio y sin duda, a la symmetria: "Haec autem ita fieri debent, ut habeautur ratio firmitatis, utilitatis, venustatis. [...]; venustatis vero, cum fuerit opere species grata et elegans / membrorunque commensus iustas habeat symmetriarum ratiocinationes"13. En las Etimologias, la venustas figura en el libro XIX, y es considerada una parte de la arquitectura, o momento de la actividad constructiva: "La construcción de edificios consta de tres momentos: la planificación, la cons-

\footnotetext{
10 VITRUVII, De Architectura libri decem, opus cit., 1976, P.L.III, pp. 132.

11 VITRUVII, De Architectura libri decem, opus cit., 1976, P.L. VI, pp. 258.

12 SAN ISIDORO DE SEVILLA, Etimologias, opus cit., pp. 8.

13 VITRUVII, De Architectura Libri Decem, opus cit., 1976, L.I, cap. III, 16-26, pp. 44.
} 
trucción y el embellecimiento (venustas)"14. No obstante, aquí nos interesa destacar que la define como un embellecimiento llevado a cabo mediante añadidos decorativos: "Embellecimiento (venustas) es todo lo que se incorpora al edificio para su ornato y decoración, como son los artesonados recamados en oro, las incrustaciones de mármol precioso o las pinturas de diferentes colores" ${ }^{15}$.

Ciertamente, para ambos autores la belleza guarda relación con el aspecto de la obra. Para el romano el aspecto está determinado por la $\tau \alpha \xi 1 \varsigma$, "formación de algún orden de cualquier tipo" ${ }^{16}$, término que ya aparecía en los textos homéricos (hacer listas, ordenar en hileras, seleccionar) ${ }^{17}$ y que Aristóteles utilizó en su Poética como "ordenación": "Praeterea vero, quoniam pulchrum et animal et omnem rem, quae ex quibusdam composita est, non solum haec ordinata habere oportet, verum etiam esse magnam, sed non quomodo libet: nam pulchrum in magnitudine et ordine consistit" ${ }^{18}$. En cambio, para el hispalense, lo agradable está vinculado al adorno extrínseco, a las incrustaciones, revestimientos, etc. ${ }^{19}$ Estos no remiten al orden ni al número ni a la proporción de la construcción, solo a su aspecto externo ${ }^{20}$, dejando ver ese doble sentido que Boecio había introducido en la estética, "disposición hermosa" y "aspecto hermoso" ${ }^{21}$, optando por el segundo.

\section{La venustas vitruviana}

Vitruvio pretende poner en orden la dispersión de normatividad arquitectónica que había en los tiempos de Augusto. Con la redacción de

14 SAN ISIDORO DE SEVILLA, Etimologias, opus cit., pp. 1276-1277.

15 SAN ISIDORO DE SEVILLA, Etimologías, opus cit., pp. 1280-1281.

16 ZELLINI, Paolo, Número y logos, Acantilado, Barcelona, 2018, pp.66.

17 HOMERO, Ilíada, Gredos, Madrid, 1996, II, 124-125, pp. 127; Odisea Gredos, Madrid, 1993, IV, 451, pp. 155.

18 ARISTÓTELES, Poética, Gredos, Madrid, 1999, 1450 b, 35-38, pp. 153.

19 ARIAS, Lorenzo, "El concepto de proporción en la Alta Edad Media" en Geometría y proporción en la Arquitectura Prerrománica Asturiana, Anejos de Archivo Español de Arqueología XLIX, CSIC, Madrid, 2008, pp. 40.

20 QUILES, Ismael, San Isidoro de Sevilla, Espasa Calpe, Buenos Aires, 1945, pp. 13.

21 TATARKIEWICZ, Władysław, Historia de la estética. II. La estética medieval, Akal, Madrid, 2007, pp. 84. su tratado, persigue dar a conocer los preceptos que los artífices de su tiempo y de la posteridad deben conocer para realizar su actividad con rigor. La arquitectura es una ciencia con ratio y teoría propias, "Ea nascitur ex fabrica et ratiocinatione"22, cuyas sus reglas habrán de observarse sopesando, con destreza y prudencia.

El núcleo de las reflexiones vitruvianas no recae en el afamado trípode utilitas, firmitas, y venustas, sino en seis conceptos: "Architectura autem constat ex ordinatione, quae graece $\tau \alpha \xi_{1 \varsigma}$ dicitur, et ex dispositione, hanc autem Graeci $\delta\llcorner\alpha 9 \varepsilon \sigma ı v$ vocitant, et eurythmia et symmetria et decore et distributione, quae graece olхovo $\mu 1 \alpha$ dicitur"23. El orden de aparición de estos conceptos es, a nuestro juicio, determinante. Vitruvio señala la ordinatio con anterioridad a la symmetria porque le interesa dejar claro que hay una actividad previa a la disposición armoniosa. "Ordinatio est modica membrorum operis commoditas separatim universeque proportionis ad symmetriam comparatio. Haec componitur ex quantitate, quae graece $\pi$ oбo $\tau \zeta$ dicitur. Quantitas autem est modolorum ex ipsius operis sumptio e singulisque membrorum est partibus universo operis conveniens effectus" ${ }^{24}$. La ordinatio, es el primero de los conceptos en tanto que, poner orden, $\tau \alpha \xi 1$, es la tarea inaugural del proceso arquitectónico. Es sabido que establecer un orden, guarda relación con el sentido primario de legein ( $\lambda \dot{\gamma} \gamma \varepsilon v v$ ): hacer una lista, ordenar en filas para luego escoger, tomar, seleccionar, "reunir y juntar". Mediante la $\tau \alpha \xi ı \zeta$ se clasifican las cosas, pero con vistas a un fin: ordenar un ejército para la batalla, ordenar el ganado para su pastoreo, ordenar las mercancías para su venta. Legein es el verbo de logos $\left(\lambda \text { ó }{ }_{0}\right)^{25}$ que es el instrumento tanto para conocer como para ordenar, por eso, conceptualmente "logos y taxis van juntos", señala Zellini $^{26}$. Cuando se ordenan y clasifican las cosas se establecen entre ellas jerarquías y relaciones. En este sentido, la ordinatio es una forma de conocer y de relacionar según cantidades, no

22 VITRUVII, De Architectura libri decem, opus cit., 1976, L. I, cap. I, 20, pp. 22.

23 VITRUVII, De Architectura libri decem, opus cit., 1976, L. I, cap. II, 10.1, pp. 36.

24 VITRUVII, De Architectura libri decem, opus cit., 1976, L. I, cap. II, 15.2, pp. 36.

25 FALUS, Robert, "La terminologie greecque du "rapport" et de la "proportion"' en Acta Antiqua Academiae Scientarum Hungaricae, XXVII, 1979, pp. 356.

26 ZELLINI, Paolo, Número y logos, opus cit., pp.38. 
en vano, número, logos y orden se hallan vinculados. En Vitruvio la ordinatio está asociada a las medidas de las partes de un edificio, membrorun, que, a nuestro juicio, son escogidas de una selección, catálogo o lista, en orden a un fin previamente establecido. Si la ordinatio no se entendiese así, las dificultades para distinguirla de la symmetria serían múltiples, no en vano, como han señalado Pollit ${ }^{27}$ y Watzinger ${ }^{28}$, podría caerse en la redundancia y sinonimia tautológica al ser ambos conceptos aritméticos. Vitruvio coloca la ordinatio al principio, porque al principio está el fin, y precisamente en orden a ese fin se escogen (nehmen) unas determinadas partes a las que se les otorgarán unas medidas concretas: toda ordenación, de suyo, tiene una utilidad, en cuya virtud unas cosas tienen una forma y no otra. Es una cuestión de cariz aritmético (quantitas) que, a nuestro modo de ver, está vinculada con el término retórico inventio y que a decir de Cicerón consiste en: "[...] encontrar lo que tenía que decir [...]"29, para "establecer una relación recíproca y la razón entre las cosas seleccionadas" ${ }^{30}$. La ordinatio variaría entonces en función del tipo de edificio pues, como se ha dicho, no es lo mismo escoger miembros de una lista de hombres para la guerra, que para la siembra, el pastoreo o la navegación. Por eso, señala Ortiz y Sanz en la nota 1 al concepto de ordinatio: "mira a las piezas de un edificio" ${ }^{31}$, vale decir, a los "elementos" o "letras", señala Platón en Filebo ${ }^{32}$.

Vitruvio nos habla en segundo lugar de la dispositio. Este término es de índole geométrica y retórica ${ }^{33}$, pero no aritmética. Para Cicerón la dispostio consiste en disponer $^{34}$ lo que la or-

27 POLLIT, Jeroneme J., The Ancient view of Greek Art: Criticism, History and Terminology, Yale University Press, New Haven and London, 1974, pp. 67.

28 WATZINGUER, Carl, "Vitruvstdiem", Rheinesches $M u$ seum fur Philologie, 64, 1909, pp. 202-223.

29 CICERÓN, Marco Tulio, Sobre el orador. Gredos, Madrid, 2002, I, 31, 144 pp. 141.

30 ZELLINI, Paolo, Número y logos, opus cit., pp.90.

31 VITRUVIO, Los diez libros de Arquitectura, Traducción de José Ortiz y Sanz, Editorial Alta Fulla, Barcelona, 1993, pp. 9.

32 PLATÓN, Diálogos VI, Filebo, Gredos, Madrid, 1992, 18 c, pp. 35.

33 CALLEBAT, Louis, Rhétorique et architecture dans le "De Architectura" de Vitruve. In: lle projet de Vitruve. Objet, destinataires et réception du De Architectura Actes du colloque international de Rome (26-27 mars 1993) Rome: Publication de l'École française de Rome, 1994, pp. 37.

34 "[...] distribuir y colocar lo hallado [...]" CICERÓN, Marco Tulio, Sobre el orador, opus. Cit., I, 31, 144-145 pp. 141. dinatio ha escogido y reunido con vistas a un fin, y para Vitruvio también, no en vano la define como distribución adecuada, elegante, de las partes de una obra: "Dispositio autem est rerum apta conlocatio elegansque compositionibus effectus operis cum qualitate" 35 . Nótese que nada dice de su proporción, tan sólo hace referencia a su disposición conveniente. Una incorrecta disposición produciría el efecto de lo deforme y lo inoportuno.

El tercero de los conceptos es la eurythmia. No obstante, vemos conveniente tratarlo después de la symmetria pues su papel es más ilustrativo tras ella. La importancia de la symmetria pone de relieve que Vitruvio no es original, ni lo pretende, y no hace más que continuar una larga y consolidada teoría del arte y de la belleza que inaugura Policleto de Argos en el s. V a.C., con lo que es considerado el primer tratado artístico, el Canon. En él afirma que la belleza está supeditada a la symmetria: "entendida como la consonancia de las partes con el todo y de estas entre sí" ${ }^{\prime 36}$. Vitruvio señala en el capítulo II del Libro I que "Item symmetria est ex ipsius operis membris conveniens / consensus ex partibusque separatis ad universae figurae speciem ratae partis responsus. Uti in hominis corpore e cubito, pede, palm, digito ceterisque particulis symmetros est eurythmiae qualitas, sic est in operus perfectionibus" ${ }^{\prime 37}$. Falus y Gross equiparan la symmetria a la "commensurabilidad" ${ }^{38}$, pues no parece posible un arte de la composición arquitectónica, ni de cualquier otra índole, sin que se dé la "armoniosa dispo-

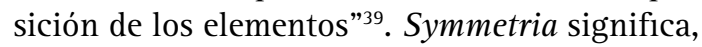
acorde de medida, justa proporción que es la igualdad de rationes vinculadas a un módulo, mediante el cual "une todos los elementos entre sí y con el todo, pudiendo este vínculo ser, por lo demás, la simple conmensurabilidad li-

35 VITRUVII, De Architectura libri decem, opus cit., 1976, L. I, cap. II, 20.2, pp. 36.

36 MONTEMAYOR, Alicia, La trama de los discursos y las artes. El Canon de Policleto de Argos. Dirección General de Publicaciones del Consejo Nacional para la Cultura y las Artes, México, 2013, pp. 139.

37 VITRUVII, De Architectura libri decem, opus cit., 1976, L. I, cap. II, 15.4, pp. 38.

38 FALUS, Robert, "La terminologie greecque du "rapport" et de la “proportion"” en opus cit., 1979, pp. $371 \mathrm{y}$ 375. GROSS, Pierre, "Les fondements philosophiques de l'harmonie architecturale selon Vitruve" en JTLA, 14, (1989), 13ff, sobre, n.4.

39 ARIAS, Lorenzo, "El concepto de proporción en la Alta Edad Media” opus cit., 2008, pp. 32. 
neal" ${ }^{40}$. En ello insiste Ortiz y Sanz en la nota 1 al capítulo II del Libro VI de Vitruvio, no en vano explica que el arquitecto "debe procurar [que los edificios] sean simétricos, esto es, bien proporcionadas sus partes con todo el edificio, y las partes menores con las mayores que componen, de manera que resulte la misma armonía de partes para la vista, que la que causa al oído un instrumento músico acorde" ${ }^{41}$.

De todas formas, la symmetria no es tan absoluta como pudiera parecer, pues como se deja ver en la segunda parte de la definición vertida en libro VI, aquella puede ser matizada e incluso corregida, lo cual no es, por otra parte, una novedad latina ${ }^{42}$. Nos dice Vitruvio en el capítulo II del libro VI que habiendo observado la symmetria, esto es la proporcionalidad de las partes entre sí y de estas respecto del todo, también resulta necesario que el arquitecto sea "prudente". Ortiz utiliza en su traducción el vocablo "perspicacia" 43 , pues quiere resaltar la agudeza visual propia del arquitecto. No obstante, nos parece más adecuado traducir literalmente el término que emplea Vitruvio, "providere", porque ese "ver lejos" o alejándose, es el que le permitirá saber si la symmetria debe ser matizada o no, añadiendo o quitando, con el fin de provocar el efecto agradable, no de la verdad de la razón métrica y normativa, sino del aspecto que produce: "Cum ergo constituta symmetriarum ratio fuerit et conmensus / ratiocinationibus explicati, tum etiam acumunis est proprium providere ad naturam loci aut usum aut speciem (detractionibus aut) adiectionibus temperaturas (et) efficere, cum de symmetria sit detractum aut adiectum, uti id videatur recte ese / formatum in aspectuque nihil desideretur" 44 .

Si se hiciese una analogía con el cuerpo humano, la symmetria señalaría la oportuna proporción de la mano respecto del brazo y de

40 GHYKA, Matila C. el número de oro. I los ritmos- II los ritos, Poseidón, Barcelona, 1992, pp. 44.

${ }_{41}$ Nota 1 de Ortiz y Sanz en VITRUVIO, Los diez libros de Arquitectura, opus cit.,1993, pp. 143.

42 La anamorfosis ya fue utilizada por Fidias en el V a.C., y por Eufranor de Istmia en el IV a.C., por Herón de Alejandría en el siglo II a.C., el matemático Gémino del siglo I a.C. y por el neoplatónico Proclo del siglo I d.C. TATARKIEWICZ, Władysław, Historia de la estética. I. La estética antigua, Akal, Madrid, 2011, pp. 286.

43 VITRUVIO, Los diez libros de Arquitectura, opus cit., 1993, pp. 143.

44 VITRUVII, De Architectura libri decem, opus cit., 1976, L. VI, cap. II, 25.2-6, pp. 270. ambos con el tamaño total del cuerpo. Es en virtud de ella que la producción de artefactos adquiere un semblante compositivo y artístico, pues en la conmensuración de todas las partes -bien ordenadas y dispuestas- recae, en gran medida, la belleza objetiva. Al ser la symmetria un concepto numérico, su observancia ofrecería suficientes garantías de perfección, tal es el carácter científico y medible de este concepto. Por eso no es de extrañar que a partir del s. V a.C., la belleza y las artes se hallen vinculadas a la symmetria, pues es a partir de entonces cuando se opera una reflexión más sistemática, cabe decir científica y técnica, de los saberes en general y de las artes plásticas en particular. Sin embargo, nos preguntamos si, a pesar de su carácter científico, la symmetria puede asegurar definitivamente la belleza. La respuesta a esta cuestión la hallamos en el concepto de eurythmia, a saber: "bello y grato aspecto y la imagen proporcional de todas las partes de la obra" ${ }^{45}$ ¿Qué papel juega en el tratado este concepto? Para Vitruvio, la eurythmia es el "resultado" 46 de la symmetria, pues se obtiene cuando es correctamente aplicada: "Eurythmia est venusta species commodusque in compo/sitionibus membrorum aspectus. Haec efficitur, cum membra operis convenientia sunt altitudinis ad longitudinem, et ad summam omnia respondent suae symmetriae" ${ }^{47}$. Nótese, y es de suma relevancia para el propósito de este artículo, que el término que aparece en el texto latino es venusta y no pulchritudo como correspondería si la belleza fuese algo rigurosamente objetivo, determinado irrestricta y absolutamente por la symmetria. La eurythmia no es solo lo que se sigue, en exclusiva, de la correcta symmetria,

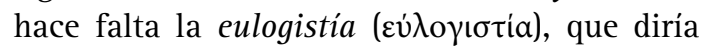
el estoico Crisipo: "el buen uso del cálculo y de la medida, la capacidad de sopesar sin perderse en los opuestos"48, en suma, prudencia. Vitruvio no es tan rígido como pudiese aparentar inicialmente, ya que su tratado participa de una idea retórica de la belleza pues, venustas no es

45 Traducción de ARIAS, Lorenzo, "El concepto de proporción en la Alta Edad Media” en Geometría y proporción en la Arquitectura Prerrománica Asturiana, Anejos de Archivo Español de Arqueología XLIX, CSIC, Madrid, 2008, pp. 32.

46 ARIAS, Lorenzo, "El concepto de proporción en la Alta Edad Media” opus cit., 2008, pp. 32.

47 VITRUVII, De Architectura libri decem, opus cit., 1976, L. I, cap. II, 10.3, pp. 38.

48 ZELLINI, Paolo, Número y logos, opus cit., pp.91. 
la belleza "trascendental", sino la apariencia visual graciosa y elegante.

Llegados a este punto podemos resumir que el De Architectura recoge la tradición griega de normas que garantizan una producción artística. Vitruvio sabe que la symmetria objetiva -de índole aritmética, geométrica y racionalpuede ser la primera instancia, pero la última será de índole retórica, y exigirá del arquitecto algo más que ciencia, a saber: ingenio, perspicacia, prudencia. 0 , dicho de otra forma, la symmetria por sí sola es capaz de alumbrar una belleza ideal, una pulchritudo, pero no una venusta. Todo ello pone de relieve que Vitruvio no era solo un ingeniero o especialista sujeto a la exclusiva regla de su disciplina. Era hombre instruido y culto $^{49}$. Ortiz y Sanz advierte, en la nota 7 del Proemio del Libro VI, que no era "esclavo ni liberto, sino ingenuo $0^{50}$, esto es, libre de nacimiento, no en vano, el sobrenombre de Polión es revelador de su carácter de libre ingenuo, pues "los Poliones fueron, señala Ortiz y Sanz, familia Romana y de alguna consideración" ${ }^{51}$. De ahí puede presumirse la notable formación cultural que le permitió familiarizarse con los principales autores griegos a los que debía conocer como su patrocinador Augusto. Sin duda, también es de suponer que le fuera familiar la doctrina de Cicerón, contemporáneo suyo. Aunque aquí no podamos detenernos sobre este particular es bien revelador que Vitruvio utilice en su trípode el término venustas y no honestum o pulchritudo. Y es que venustas es un término asociado a la elocuencia y, en suma: a la gracia, la elegancia y el encanto. Estos conceptos, gracia y encanto, no son ni tan objetivos ni tan científicos o absolutos como pudiese pensarse a primera vista, sin que ello suponga caer en la irracionalidad. Son de otra índole, la discursiva, no en vano ratio y oratio son términos afines ${ }^{52}$.

Insistamos: el tratado vitruviano deja ver que la belleza objetiva de la symmetria está más próxima a la pulchritudo que a la venustas.

49 VITRUVIO, Los diez libros de Arquitectura, opus cit.,1993, pp. XVI.

50 VITRUVIO, Los diez libros de Arquitectura, opus cit.,1993, pp. 137.

51 VITRUVIO, Los diez libros de Arquitectura, opus cit.,1993, pp. XVI. Sobre esta cuestión, MORTET, Victor, "Recherches critiques sur Vitruve et son ouvre" en Revue archéologique, II, Vitruve et les vitruvius, (1902), pp. 53-54.

52 ZELLINI, Paolo, Número y logos, opus cit., pp.62.
Hace falta algo más que la mera observación de la teórica y científica normatividad para que la venustas aparezca. Ese algo más es la matización de la norma, lo que exige perspicacia, ingenio y buen gusto. El carácter legal de la ordinatio, de la dispositio y de la symmetria no son suficientes para garantizar la gracia o el encanto. Estos no se alcanzan con la sola teoría, pues también interviene la puesta en escena, saber aplicar los preceptos, las reglas y las leyes a una situación y un contexto particular. En suma, la objetividad de la symmetria, por sí sola, guardaría relación con la noción de pulchritudo: una belleza absoluta. En cambio, la eurythmia lo hace con la venustas, una belleza graciosa y elegante, ajustada a su contexto, de "sutil encanto y desenvoltura" 53 , diría Cicerón, “[...] gracias a soluciones espontáneas del ingenio [acuminibus ingeniorum] y no mediante la relación de reglas estrictas" ${ }^{54}$, nos dice Vitruvio.

\section{Pulchritudo y venustas}

La diferencia entre la pulchritudo y la venustas es sustancial. Hasta el siglo $\mathrm{V}$ a. C., en los textos homéricos y en las Odas de Píndaro, hallamos una noción de belleza ( $\kappa \alpha \lambda o ́ v$ ) que no permite distinguir el eîdos de la morphé y la phýsis. De hecho, no cabe pensar una belleza, en tanto que mero aspecto, sino en todo el ser de la cosa, aunque sea una téchne ónta ${ }^{55}$. En la Grecia clásica, comienza a considerarse otra belleza, más científica, como pusieron de relieve los primeros tratados técnicos del s. VI a. C, y sobre todo el Canon de Policleto en el V a. C. Esta noción de lo bello relacionado con la proporción, las dimensiones y el orden, sin duda después de hacer muchos cálculos ( $\pi \mathrm{o} \lambda \lambda \bowtie v$ $\dot{\alpha} \rho(\theta \mu \omega)$, es la que hace referencia a lo que grie-

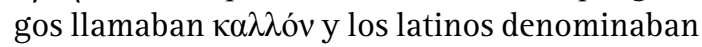
pulchrum, términos bien distintos de venustas. Tatarkiewicz nos dice que utilizaban "[...] unos

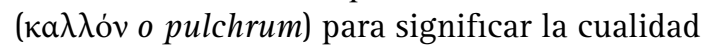

53 CICERÓN, Marco Tulio, Sobre el orador, opus cit., I, 4, 17, pp. 92.

54 Traducción al concepto de eurythmia de ARIAS, Lorenzo, "El concepto de proporción en la Alta Edad Media" opus cit., 2008, pp. 32.

55 MÍGUEZ, Aida, "El cuerpo como problema hermenéutico en la lectura de los poemas homéricos" en Eidos, no 25, 2016, pp. 247. También en KONSTAN, David, "El concepto de belleza en el mundo antiguo y su recepción en Occidente" en Nova Tellvs, 30-1, 2012, pp. 133-148. 
abstracta de la belleza, y otro para referirse a una cosa bella en particular" ${ }^{\prime 5}$. La pulchritudo es esencialista y guarda relación con la pura objetividad, ideal, perfecta y absoluta; es la "belleza objetiva" y está emparentada con la symmetria y con la "eurythmia real y mensurable" ${ }^{57}$. A priori, la symmetria y la pulchritudo son indiscutibles y están unidas al ser por el orden, la dimensión y la proporción. En cambio, la venustas está sujeta a la adecuación con el mundo real, a sus situaciones y sus contextos particulares, por eso se halla vinculada a la "eurythmia óptica" ${ }^{58}$ y al decoro. La pulchritudo es más independiente de la percepción, es objetiva. Es un término aritmético, geométrico y racional como lo son la ordinatio, la dispositio y la symmetria. Tiene el rango de lo mental y lo abstracto, tal es el sentido de la idea de belleza que recoge Platón en el Banquete y en Hipias Mayor. Aristóteles también incide en esta cuestión. Lo hace en Tópicos III -vinculando la noción de belleza a la de proporción (symmetria $o$ conmensuratio)- por eso utiliza el término pulchritudo (traducción de Boecio): "Pulchritudo membrorum quaedam conmensuratio videtur ese" ${ }^{59}$, "La belleza parece ser cierto equilibrio de los miembros" ${ }^{60}$. El estagirita apunta en el mismo sentido en Metafísica. En el Libro V sentencia: "Y es que el bien y la belleza son principio [...]"61; en el XII afirma que "[...] no opinan acertadamente quienes suponen, como los pitagóricos y Espeusipo, que lo más perfecto (bello) y mejor (bueno) no se encuentra en el principio" ${ }^{2}$, y en el XIII leemos que "[...] las formas supremas de la belleza son el orden, la proporción y la delimitación, [...]"63. En Poética también utiliza el término pulchrum al señalar que: "Además, puesto que lo bello (pulchrum), tanto un animal como cualquier cosa compuesta de partes, no sólo debe tener orden en éstas,

56 TATARKIEWICZ, Władysław, Historia de seis ideas. Arte, belleza, forma, creatividad, mímesis, experiencia estética, Tecnos/Alianza, Madrid, 2004, pp. 153.

57 ARIAS, Lorenzo, "El concepto de proporción en la Alta Edad Media” opus cit., 2008, pp. 32.

58 ARIAS, Lorenzo, "El concepto de proporción en la Alta Edad Media” opus cit., 2008, pp. 32.

59 BRUYNE, Edgard de, La estética de la Edad Media, Antonio Machado Libros, Madrid, 2010, pp. 26.

60 ARISTÓTELES, Tópicos, Gredos, Madrid, 1982, 116b20, pp. 147.

${ }^{61}$ ARISTÓTELES, Metafísica, Gredos, Madrid, 2011, 1013a, pp. 211.

62 ARISTÓTELES, Metafísica, opus cit., 1072b, pp. 492-493.

63 ARISTÓTELES, Metafísica, opus cit., 1078b, pp. 518. sino también una magnitud que no puede ser cualquiera; pues la belleza (pulchrum) consiste en magnitud y orden" ${ }^{\prime 4}$. Vitruvio debió dominar, aunque solo fuese moderadamente, estos textos y otros muchos pues, como hemos señalado, era hombre instruido y culto, y como romano debió sentir, igual que su patrocinador Augusto ${ }^{65}$, una profunda admiración por los textos griegos. Es de suponer que también le fuesen familiares los textos de los estoicos para quienes "la symmetria representaba la belleza absoluta, el decorum la relativa ${ }^{66}$. Para los estoicos, era relativa exclusivamente respecto a su objeto [...], afirmando que cada cosa en particular tiene su decorum dependiente de su naturaleza, e independiente por el contrario del tiempo, de las condiciones o del sujeto que se sirve de él"67. También debió conocer la definición que Cicerón ofreció de la belleza y su vínculo con la pulchritudo: "[...] así como la hermosura (pulchritudo) y buena disposición de un cuerpo atrae los ojos y deleita por la gracia y armonía con que están hermanados unos miembros con otros [...]"68. Esta definición era, por otra parte, bien equivalente a la de Aristóteles en los Tópicos y a la de eurythmia vitruviana que más arriba hemos tenido oportunidad de señalar.

En cualquier caso, aunque Platón, Aristóteles y Cicerón ofrecen una definición de belleza muy objetiva y ligada a la symmetria, como de hecho sucede con Vitruvio, todos ellos abren la posibilidad de la venustas y del decoro. El primero en Hipias Mayor, el estagirita en Retórica, y Cicerón en Los oficios y en Sobre el orador. Platón consigue que Sócrates le urja a Hipias en estos términos: "Explícame adecuadamente qué es lo bello en sí mismo y, al responderme, procura hablar con la máxima exactitud [...]"69. Sin embargo, Sócrates vacila durante el diálogo llegando a sentenciar que quien solo se preocupa por la verdad (y lo bello en sí) es "des-

${ }^{64}$ ARISTÓTELES, Poética, Gredos, Madrid, 1999, 1450 b, 35-38, pp. 153.

65 ZANKER, Paul, Augusto y el poder de las imágenes, Alianza Forma, Madrid, 1992.

66 BRUYNE, Edgard de, La estética de la Edad Media, opus cit., 2010, pp. 45.

67 TATARKIEWICZ, Władysław, Historia de la estética. I. La estética antigua. Akal. Madrid, 2011, pp. 197.

${ }_{68}$ CICERÓN, Marco Tulio, Los oficios, Espasa Calpe. Madrid, 1959, pp. 62.

69 PLATÓN, Diálogos I: Hipias Mayor, Gredos, Madrid, 1985, 286 d-e, pp. 412. 
atildado y grosero"70, maleducado e inoportuno. La sospecha se hace más profunda cuando Sócrates empieza a dudar de una conveniencia absoluta y del carácter definitivo de la belleza. Platón introduce en esta parte del diálogo el término "adecuado". Puede que existan cosas que tengan mucho valor como el oro, pero eso no quiere decir que este deba utilizarse indiscriminadamente. El oro, recuerda Platón, no es oportuno ni adecuado para hacer la cuchara de una olla, pues es más conveniente que esta sea de madera, porque da más sabor a los alimentos y no rompe la olla ${ }^{71}$. Platón añade el ejemplo de la estatua de Atenea que Fidias esculpió en el Partenón ¿Acaso no sabía el escultor que el oro es más bello que el marfil? Sin duda, pero no era adecuado. “¿No es cierto [...] que el marfil y el oro [...] cuando son adecuados hacen que las cosas aparezcan bellas y cuando no son adecuados, feas?", se pregunta Sócrates. A Hipias no le resta más que responder que: "Vamos a admitir que lo que es adecuado a cada cosa eso la hace bella" ${ }^{2}$. Como se ve, en el texto platónico se produce el deslizamiento de lo en sí a lo adecuado, de la pulchritudo a la venustas, por cuanto esta guarda relación con lo oportuno, lo que conviene y es adecuado.

Aristóteles señala en Retórica que el hombre puede elegir entre lo bello, lo agradable y lo útil. Aunque lo bello se imponga por sí mismo $^{73}$ y se elija por sí mismo ${ }^{74}$, lo agradable y lo útil se eligen por relación o adecuación oportuna a otra cosa. Cicerón también advierte la dificultad de lo adecuado y lo oportuno al definir el decorum, término equivalente a la venustas. Nótese en este punto la ilustrativa definición que hace de inoportunidad en el libro segundo de Sobre el orador: "Pues quien no ve qué es lo que exige cada ocasión o habla más de la cuenta, o hace ostentación de sí mismo, o no tiene en cuenta la consideración y los intereses de quienes le rodean, o quien en fin, en algún punto desafina o exagera, ese recibe el nombre de inoportuno"75. Aunque aquí no podamos ex-

70 PLATÓN, Diálogos I: Hipias Mayor, opus cit., 288 d, pp. 415.

71 PLATÓN, Diálogos I: Hipias Mayor, opus cit., 290 e, pp. 418.

72 PLATÓN, Diálogos I: Hipias Mayor, opus cit., 290 d, pp. 418.

73 ARISTÓTELES, Retórica, Gredos, Madrid, 1999, 1363b, pp. 223.

74 ARISTÓTELES, Retórica, opus cit., 1366a, pp. 241.

75 CICERÓN, Marco Tulio, Sobre el orador, opus cit., II, 4, 17, pp. 210. tendernos más, baste con señalar que para el retórico romano la belleza en sí (pulchritudo) tiene su equivalente en el término honestum, mientras que la belleza adecuada y oportuna (venustas) lo tiene en el decorum (término que también utiliza Vitruvio), no obstante, aquel subyace a este ${ }^{76}$. Con todo, hay un último ejemplo de los muchos que se podrían citar de Cicerón ${ }^{77}$, que serviría para hacernos cargo de su sentido retórico de venustas, también de decorum, y que a nuestro juicio es al extremo perfectamente compatible y equivalente con la noción de venustas vitruviana. En Sobre el orador introduce el término placer (deleitar) asociado a la venustas cuando constata que hay algo más allá de la utilidad capaz de provocar un fin último: "Dejemos el mundo de la naturaleza y acudamos a las artes. ¿Qué hay en una embarcación tan necesario como sus flancos, como sus cuadernas, su proa, su popa, sus antenas, sus mástiles? Y sin embargo tienen un encanto (venustatem) cuando se las mira, que parece que se han ideado no solo para la seguridad sino para el placer"78.

La venustas no cuestiona la condición objetiva $^{79}$ de la belleza, más bien la sitúa en la órbita del "juicio de nuestros propios ojos" ${ }^{80}$, de la delectación, (delectare, señala de Bruyne ${ }^{81}$ ). $\mathrm{Y}$ así es señalado por Vitruvio: "venustatis vero, cum fuerit opere species grata et elegans / membrorunque commensus iustas habeat symmetriarum ratiocinationes" 82 , y comentado por Ortiz y Sanz: "Luego siendo simétrico en sus

76 CICERÓN, Marco Tulio, Los oficios, opus cit. pp. 60-61. 77 GROS, Pierre, La rhétorique des ordres dans l'architecture classique: Colloque sur la rhétorique. Calliope I (= Caesarodunum, XIV bis), Paris, 1979, p. 333-347 In Vitruve et la tradition des traités d'architecture: Fabrica et ratiocinatio (en línea). Rome: Publications de l'École française de Rome, 2006 (generado el 15 janvier 2020). Disponible en Internet: http://books.openedition.org/ efr/2501. ISBN: 9782728310289. DOI: 10.4000/books. efr.2501.CALLEBAT, Louis, Rhétorique et architecture dans le "De Architectura" de Vitruve. Opus cit., 1994, pp. 34 y 37.

78 CICERÓN, Marco Tulio, Sobre el orador, opus cit., III, 46, 180, pp. 462.

79 TATARKIEWICZ, Władysław, Historia de la estética. I. La estética antigua, opus cit., 2011, pp. 283.

${ }^{80}$ ARIAS, Lorenzo, "El concepto de proporción en la Alta Edad Media” opus cit., 2008, pp. 32.

${ }^{81}$ BRUYNE, Edgard de, Historia de la Estética. I: La antigüedad griega y romana, BAC, Madrid, 1963, pp. 286.

82 VITRUVII, De Architectura libri decem, opus cit., 1976, L.I, cap. III, 16-26, pp. 44. 
partes el edificio, y agradable en sus perfiles, será eurítmico o gracioso" ${ }^{83}$.

\section{La arquitectura para Isidoro de Sevilla: diferencias y similitudes}

Isidoro de Sevilla señala que en la arquitectura hay tres fases: “[...] la planificación (dispositio), la construcción (constructio) y el embellecimiento (venustas)" ${ }^{84}$. Los tres términos aparecen en el tratado de Vitruvio. No obstante, las diferencias conceptuales, sobre todo respecto a la dispositio y la venustas, nos llevan a pensar que, o bien Isidoro no se hizo cargo del sentido de los conceptos arquitectónicos vitruvianos, o sencillamente los manejaba a través de otros textos que pudieron haberlo interpretado de forma diferente.

Como hemos tenido oportunidad de señalar, la dispositio es defınida por el tratadista romano como una cuestión geométrica y no constructiva. Sin embargo, para Isidoro de Sevilla guarda relación con el suelo (solar) y con la cota de cimentación o firme sobre el que asentar el edificio. Para Vitruvio, la dispositio no es un concepto constructivo, no en vano es definida, como se ha apuntado más arriba, en los siguientes términos: "Dispositio autem est rerum apta conlocatio elegansque compositionibus effectus operis cum qualitate" ${ }^{25}$. Habrá que esperar al último de los seis conceptos del tratado vitruviano, la distributio, para hallar una referencia a los materiales de construcción, a la elección de piedras y arenas o maderas de la región, también a la elección del solar o lugar adecuado, según el rango social de sus moradores: "Distributio autem est copiarum locique commoda dispensatio parcaque in operibus sumptus ratione temperatio" ${ }^{86}$. La referencia a los cimientos aparece referida en la firmitas, y guarda relación con la adecuada cimentación y también con la conveniente utilización de materiales: "Firmitatis erit habita ratio, cum fuerit / fundamentorum ad solidum depressio, quaque e materia, copiarum sine avaritia diligens elec-

83 Nota 4 al término "hermosura" en VITRUVIO, Los diez libros de Arquitectura, opus cit.,1993, pp. 14.

84 SAN ISIDORO DE SEVILLA, Etimologias, opus cit., pp. 1276-1277.

85 VITRUVII, De Architectura libri decem, opus cit., 1976, L. I, cap. II, 20.2, pp. 36 .

86 VITRUVII, De Architectura libri decem, opus cit., 1976, L. I, cap. II, 10.8, pp. 42 tio;" ${ }^{87}$. Vitruvio también alude a la cimentación de los edificios en el capítulo VIII del libro VI. Allí nos dice que "el mayor cuidado del Arquitecto debe ser en orden a la estructura de los cimientos" ${ }^{\prime 8}$. Por tanto, el sentido que Isidoro otorga a la dispositio se aleja notablemente del que Vitruvio le concede en su tratado. Más aún, dado que el romano es muy explícito cuando hace referencia al terreno y a la estabilidad del firme, dudamos que el hispalense manejase en este punto directamente el tratado vitruviano. Al definir la constructio, el hispalense hace mención a la edificación de paredes y a la altura, esto es: vincula la construcción con la ejecución de los paramentos verticales, bien sean interiores, bien sea la ejecución de fachadas. Unas y otras precisan de maestría, pues la altura de las mismas se halla subordinada el espesor. A mayor altura se exige mayor grosor, lo que sin duda precisa dominio de la traba, del aparejo y de la conjunción de materiales. Este apartado, desde el punto de vista técnico es bien notable pues, aunque la estabilidad del edificio recae en un adecuado apoyo en suelo firme, la estabilidad vertical depende del espesor de los muros o paramentos verticales, sobre todo si se construye, y tal era el caso, con elementos que trabajaban por peso, es decir a compresión pura. Sobre este particular no cabe dudar de las coincidencias entre Vitruvio e Isidoro, aunque no por fidelidad al texto vitruviano sino porque la técnica constructiva no había variado en lo sustancial entre el siglo I a. C. y el siglo VII. Con todo, son dignas de mención algunas similitudes. Sobre la construcción de paredes hay coincidencias en el punto 8 del libro XIX de las Etimologías y el capítulo VIII del Libro II del tratado vitruviano. En el punto 10.2 del libro XIX -referente a los cimientos, piedras, cal y arena- vemos parecidos al capítulo III del libro III del tratado romano. Los puntos 10.19 referidos a la cal viva, el 10.14 a la Arena de río y 10.25 cuyo tema son los pavimentos ofrecen semejanzas con el capítulo $\mathrm{V}$ del libro II, el capítulo IV del libro II y el capítulo I del libro VII del texto vitruviano. También son de destacar algunas coincidencias en torno a los colores naturales y artificiales. El punto 17.2 del libro XIX de las Etimologías puede hallarse

\footnotetext{
${ }^{87}$ VITRUVII, De Architectura libri decem, opus cit., 1976, L.I, cap. III, 16-26, pp. 44.

88 Traducción nuestra de VITRUVII, De Architectura libri
} decem, opus cit., 1976, L.VI, cap. VIII, 24-26, pp. 294 
más desarrollado en el capítulo VII del Libro VII de Vitruvio. Finalmente, el punto 17.2, referente a los colores artificiales, ofrece semejanzas con el capítulo X del libro VII del tratado de arquitectura. Llama la atención que, en cambio, el punto 10.16 de las Etimologías que trata de los ladrillos no halle equivalente, ni conceptual ni técnico con el capitulo III del libro II de la obra escrita de Vitruvio. También es llamativo que en el libro XV del hispalense, destinado a las construcciones rurales, y en concreto el punto 8 destinado a reseñar las Partes que componen un edificio no se halle referencia alguna explícita a Vitruvio. En resumen, las coincidencias constructivas no son literales y a veces muy puntuales, lo que viene a corroborar que Isidoro de Sevilla no tomó como referencia directa el tratado vitruviano sino, así lo defiende Isabel Velázquez, a otros autores como Plinio y Paladio $^{89}$ que sí pudieron basarse en él directamente.

\section{La venustas arquitectónica en Isidoro de Sevilla}

En los epígrafes anteriores hemos tratado la noción de belleza vitruviana. Se ha advertido que la teoría de Vitruvio, aunque inicialmente pudiera estar vinculada a la pulchritudo o belleza objetiva, acabaría revelando una visión estética que, sin invalidar la fundamentación objetiva, también estaba orientada a la delectación. Se ha adelantado que la eurythmia, el "resultado de la symmetria", no se conquista mediante añadidos u ornamentos externos a la sustancia arquitectónica, sino mediante symmetria, decoro, adecuación y oportunidad. A veces, harán falta ciertas matizaciones. Estas correcciones a la symmetria (anamorfosis), son correcciones de proporcionalidad, y no un mero embellecimiento o aderezo extrínseco. $Y$ es que hay una notable diferencia entre la noción de belleza y la de embellecimiento. No obstante, ambos autores utilizan el término venustas, lo que nos lleva a pensar que la influencia vitruviana en el texto del hispalense es más débil de lo que pueda parecer.

En el libro XIX de las Etimologías se indica que la belleza (venustas) es un añadido, addi-

${ }_{89} \quad$ VELÁZQUEZ, Isabel, “Aedificiorum venustas: la recepción de un término clásico en Isidoro de Sevilla (Etym., XIX 11), opus cit., pp. 240. $t_{u r^{90}}$. Si es lo que se añade a la construcción, entonces no es sustancial, tal es el carácter que el hispalense otorga a "[...] todo lo que se incorpora al edificio para su ornato y decoración, como son los artesonados recamados en oro, las incrustaciones de mármol precioso o las pinturas de diferentes colores" ${ }^{\prime 1}$. Isidoro dedica a la venustas la última parte de su definición de arquitectura, señalado que el embellecimiento es el tercero de los "momentos" del quehacer arquitectónico. Este es el punto en el que más discrepancias, sobre todo conceptuales, ofrece respecto al tratado vitruviano. Esta notable desemejanza conceptual también nos lleva a pensar que aquel no manejó directamente el texto de Vitruvio, y si lo hizo a través de otros autores, estos tampoco lo comprendieron.

Aunque Isidoro vincula la etimología de venustus del libro X con la puchritudo, es decir con lo bello en sí, la definición de venustas contenida en el libro XIX, y que más arriba hemos tenido oportunidad de señalar, es la que más relación tiene con el embellecimiento. $\mathrm{Al}$ describir La construcción de edificios indica que el primer momento es la disposición, el segundo es la construcción y el tercero es el embellecimiento. Estos tres momentos conciernen a lo que actualmente se llamaría, proyecto $\mathrm{y}$ ejecución de cimentación, construcción aérea y finalmente decoración. Nótese que el embellecimiento o venustas ha sido desplazado al final. El motivo es obvio: si la decoración es lo que se incorpora o añade a la obra, primero habrá de estar ejecutada. Sin embargo, para Vitruvio el sentido de la venustas no es de índole superficial. La gracia, el encanto y la sutileza no recaen en el aspecto de lo que se añade sino en la adecuada y conveniente observancia de la symmetria, lo que no impide que esta sea matizada, pulida e incluso corregida. La aplicación de reglas no es mecánica sino inventiva, pues requiere ingenio, término por otra parte muy retórico, como puede comprobarse en los textos ciceronianos. Adviértase que Vitruvio, al final de su definición de dispositio, trae a colación el término retórico inventio: "Inventio autem est quaestionum obscurarum explicatio ratioque novae rei vigore mobili reperta (ingenio o ágil

\footnotetext{
SAN ISIDORO DE SEVILLA, Etimologias, opus cit., pp. 1280.

91 SAN ISIDORO DE SEVILLA, Etimologias, opus cit., pp. 1280-1281.
} 
inteligencia)" ${ }^{92}$ y en el capítulo II del libro VI escribe, a propósito de la relevancia de la sensibilidad que: "Haec autem etiam ingeniorum acuminibus, non solum doctrinis efficiuntur" ${ }^{93}$, dicho de otro modo: la venustas eurítmica también precisa invención e ingenio. Este punto es determinante para una comprensión de la venustas en clave retórica, que es la que, a nuestro juicio, defiende Vitruvio y no termina de vislumbrarse en la obra de Isidoro, probablemente tampoco en la de Plinio o Paladio. Más aún, Isidoro utiliza en la definición de venustas el término "ornato": "Embellecimiento es todo lo que se incorpora al edificio para su ornato y decoración". El sentido del ornato como lo que se añade es corroborado por el hispalense en el punto 30 del mismo libro XIX referido a los "adornos", no en vano, indica que "Se denominan adornos (ornamenta) porque con ellos se embellecen los rostros (ora) y el aspecto externo de las personas" 94 .

\section{Conclusión: el ornato como inventio}

Sin embargo, esta concepción del ornato no se corresponde en Vitruvio con lo que se incorpora, sino más bien con lo que se deja ver, con lo que se hace visible. Para Vitruvio $\mathrm{y}$, a nuestro modo de ver, para Cicerón, el sentido del ornato se halla intimamente ligado a la elocuencia que es la que alumbra y deja ver la retórica pues "la elocuencia no ha nacido de la técnica retórica, sino la retórica de la elocuencia" 95 ¿Qué es propiamente el ornatus? $\mathrm{Si}$ estuviésemos exclusivamente inmersos en un marco metafísico o científico como el que corresponde a la pulchritudo, no cabría más opción que relacionar el ornato con lo superficial y secundario. No obstante, el ornatus está ligado a la inventio. Ambos son términos vinculados a la elocuencia clásica y, por tanto, no deberían relacionarse solo con el concepto de creación sino con el de descubrimiento ${ }^{96}$. La

92 VITRUVII, De Architectura libri decem, opus cit., 1976, L. I, cap. II, 20.2, pp. 36.

93 VITRUVII, De Architectura libri decem, opus cit., 1976, L. VI, cap. II, 27, pp. 272.

94 SAN ISIDORO DE SEVILLA, Etimologias, opus cit., pp. 1313.

95 CICERÓN, Marco Tulio, Sobre el orador, opus cit., I, 32, 146, pp. 142.

96 SHINNER, Larry, La invención del arte. Una historia cultural, Paidós, Barcelona, 2016, pp. 81. inventio consiste en el desvelamiento o descubrimiento de un orden de relaciones. Dicho de otra forma, la venustas euritmica no aflora solo a través de la symmetria, sino a través de la inventio y del ingenio elocuentes: "[...] gracias a soluciones espontáneas del ingenio [acuminibus ingeniorum] y no mediante la relación de reglas estrictas” dice Vitruvio. El ornato es lo que se ve o aparece cuando se dice bien o se hace bien el trabajo, y se asemeja a lo que se muestra como si de un principio o arché se tratase. No es casualidad que ornatus

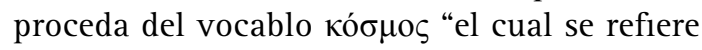
[desde el punto de vista ontológico] a la relación entre las partes y el todo y designa el orden particular que existe entre ellos"97. Lo que aparece mediante el saber hacer elocuente es lo que Heráclito llamaba kósmos, la estructura interna de las cosas, la proporcionalidad, el orden, también el logos, el juntar y unir. Solo cuando el kósmos se hace visible brota la gracia (kháris), la elegancia, lo sutil y encantador. Más aún, dicho orden de proporcionalidad o kósmos aflora en la poiesis oportuna y adecuada, en la correcta relación y ajuste con la situación y circunstancia concreta en la que tiene lugar el saber hacer artesanal y

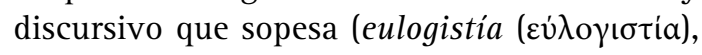
providere).

Este sentido de lo proporcionalidad y de lo oportuno recae en el ingenio del genio que no opera, ni ciega ni mecánicamente ni mediante la abstracción, dado que no puede actuar sine rerum usu, anota Grassi ${ }^{98}$. Ese "vigore mobili reperta", que es inesperado y espontáneo, que se puede conocer, pero no se puede enseñar, que "no puede conseguirse por técnica pues es un don de la naturaleza"99 es el que da lugar a la "venusta species commodusque (...) aspectus" ${ }^{100}$, a lo agradable de ver.

Adornar, ornamentar o embellecer no es, en rigor, añadir ni incorporar. La belleza no es algo añadido al orden, sino lo que se consigue al juntar las cosas reconociendo su orden. No es el último de los momentos del quehacer arquitectónico. Más bien es el principal, y reco-

\footnotetext{
97 GRASSI, Ernesto, Retórica como filosofía. La tradición humanista, Anthropos, Barcelona, 2015, pp. 111.

98 GRASSI, Ernesto, Retórica como filosofía. La tradición humanista, opus cit., pp. 12.

99 CICERÓN, Marco Tulio, Sobre el orador, opus cit., I, 25, 114, pp. 131-132.

100 VITRUVII, De Architectura libri decem, opus cit., 1976, L. I, cap. II, 10.3, pp. 38.
} 
rre todo el proceso creativo y operativo, pues consiste en sacar a la luz, descubriendo e "inventando" la naturaleza de las cosas hacien-

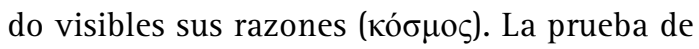
que eso se ha hecho es que brota la venustas, el brillo o gracia, y este es el sentido sustancial que, a nuestro juicio, le otorgaba Vitruvio, tal es su inspiración retórica, frente al que le concedió Isidoro de Sevilla, más superflua y cosmética. 